\title{
Polymer coating over solid particles with in situ thermal curing
}

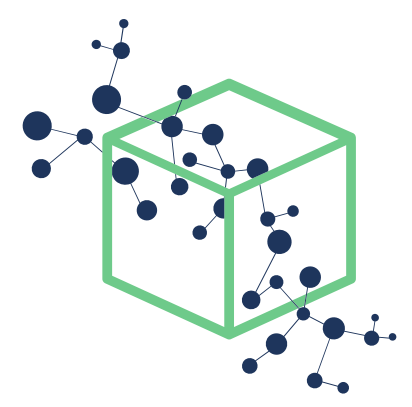

XI RESEARCH

http://xiresearch.org

This document is the accepted manuscript (after peer review) version of an article published in its final form (i.e., the version of record) by American Chemical Society as

Shimiao Zhang, Lily Lai Chi So, Santiago Faucher, and Li Xi. Polymer coating over solid particles with in situ thermal curing. Industrial \& Engineering Chemistry Research, 55:55745584, 2016. doi: 10.1021/acs.iecr.6b00376

(copyright @ 2016, American Chemical Society). The version of record is hosted at

https://dx.doi.org/10.1021/acs.iecr.6b00376

by the publisher.

The current version is made available for your personal use only in accordance with the publisher's policy. Please refer to the publisher's site for additional terms of use.
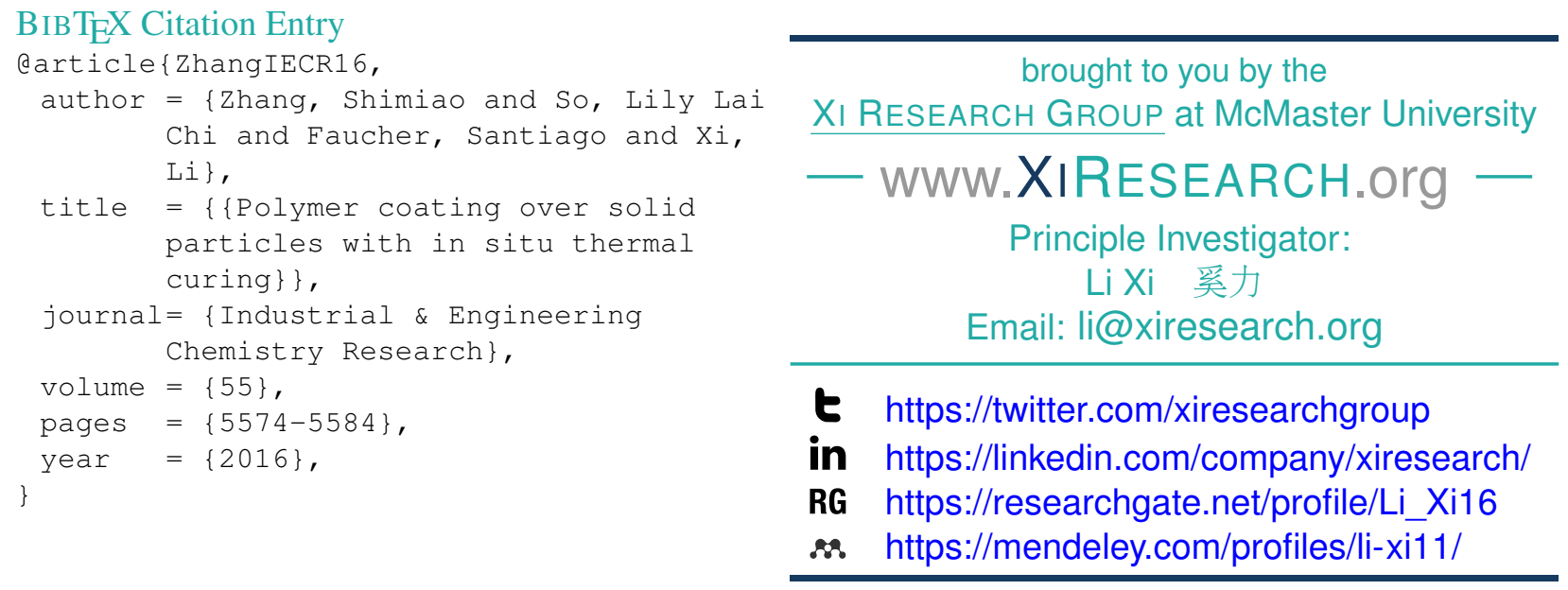


\title{
Polymer Coating over Solid Particles with In-Situ Thermal Curing
}

\author{
Shimiao Zhang ${ }^{1}$, Lily Lai Chi So ${ }^{2}$, Santiago Faucher ${ }^{2}, \mathrm{Li} \mathrm{Xi}^{1 *}$ \\ ${ }^{1}$ Department of Chemical Engineering, McMaster University, Hamilton, ON L8S 4L7 Canada \\ ${ }^{2}$ Hatch Ltd., Mississauga, ON L5K 2R7 Canada
}

Abstract

Solid particles coated by crosslinked polymer layers find applications in many areas including hydraulic fracturing operations. In this study, a hot-melt resin coating process for solid particles is developed and optimized for hydraulic fracturing application. Phenolic resin is used to coat the particles above its melting point and subsequently cured in-situ by hexamethylenetetramine (HMTA). The coating quality is then characterized by surface morphology, acid solubility and crush resistance of the resin-coated particles. Effects of various operating parameters on the coating performance are systematically studied. Among them, temperature is shown to play an especially important role. The coating process involves intricate coupling between resin rheology, HMTA mass transfer and curing kinetics, all of which are profoundly influenced by temperature. Different constant temperature levels as well as controlled temperature ramps are investigated and the results show a complex dependence. Higher temperature leads to stronger coating layers with better barrier properties whereas lower temperature is preferable for better surface morphology. These two trends can be partially reconciled with ramping temperature profiles; the improvement is however eventually limited by the rate of heat transfer. This study not only provides insight into the physical and chemical processes underlying the resin coating operation, it also demonstrates a generalizable strategy suitable for various particle coating processes.

Keywords: organic coating, thermal curing, solid particles, process development, polymers, oil and gas

* Corresponding author: xili@mcmaster.ca 


\section{Introduction}

Inorganic and organic coating technologies are extensively used for the purpose of surface protection, decoration and functionalization ${ }^{1}$. Compared with coating on flat surfaces ${ }^{2}$, coating of three-dimensional objects such as solid particles or granular materials has been much less studied. Our interest in these materials is particularly motivated by their application in the hydraulic fracturing (fracking) operations ${ }^{3}$. During fracking operations, a highly pressurized liquid mixed with additives is pumped into the well to induce the fracturing of the surrounding rock formations. These cracks provide pathways for the release of oil or gas locked behind the formations, allowing the exploitation of reservoirs inaccessible to conventional oil recovery techniques. Small granules, also known as proppants, are injected with the fluid, which stay in the cracks and hold them open after the pressure is removed. Ideal proppants should have sufficient mechanical strength and chemical stability to sustain the high pressure and acidity of the downhole environment. Meanwhile cost is often also a crucial consideration. Common choices for proppants include river sands, walnut hulls, glass beads and many other synthetic particles such as sintered bauxite and ceramics ${ }^{4-6}$. Proppants coated with one or more resin layers are also being developed for enhanced resistance to chemicals and high closure pressure and better proppant flowback control ${ }^{5}$. Flowback of proppants after hydraulic fracturing is an undesired process in which the particles flow out of the fractured zones and enter the wellbores with the produced fluids, leading to reduced well productivity and damage to production equipment ${ }^{7,8}$. The resin coating layers not only serve as protective shells for the proppants, but also provide grain-to-grain bonding interactions that prevent their flowback. In the event of proppant crushing, these layers also act as cages to encapsulate the crushed fines. All of these lead to improved well productivity ${ }^{4,5}$. Meanwhile, compared with the proppant substrate, which

often comes at little to no cost by itself, resins are much more expensive and their usage can significantly drive up the overall $\operatorname{cost}^{6,9}$. Excessive resin usage also causes environmental concerns as it may detach from the proppants, decompose, and chemically contaminate the surrounding soil and water sources ${ }^{10,11}$. It is thus important to minimize the resin dosage in proppant coating processes. Coating of solid particles of similar sizes (micron to millimeter) also finds applications in many other fields, such as polymer-coated drug particles for controlled drug release ${ }^{12,13}$, 
titania-coated glass beads for waste water treatment ${ }^{14}$, chitosan-coated perlite beads for heavy metal adsorption ${ }^{15,16}$, and resin-coated metallic cores for ion-exchange applications ${ }^{17}$.

Coating performance is determined by a range of factors, including the rheology of the coating materials, substrate surface properties, curing reaction kinetics (if introduced), and coating technique ${ }^{18-20}$. For solid particles, common

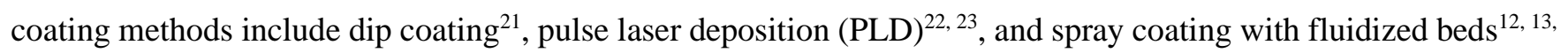
24, 25. Chemical cross-linking or curing is often induced during or after the coating process for enhanced coating layer properties. Although curing can be triggered by multiple means ${ }^{26-29}$, heat-induced or thermal curing remains the most widely-used. At least for flat surfaces, coating process incorporating thermal curing has been studied for various polymer coating materials, such as epoxies, polyurethanes, silicones, and polyimides ${ }^{28,29}$. Over the years, much effort has been dedicated to understanding the effects of operating parameters such as curing temperature and curing time on the outcome of the coating ${ }^{30-34}$. Lee et al. ${ }^{35}$ prepared epoxy-based and polyurethane-based coatings on glass plates by means of powder coating. The development of coating surface structure was found to depend on both the conversion of the curing reaction and on the isothermal complex viscosity of the coating layer. Also for the powder coating of epoxy-based systems, Barletta et al. ${ }^{36}$ found that although film morphology was insensitive to baking temperature and was determined at the early stage of curing, mechanical properties of the film depend strongly on both the baking temperature and curing time, through which the degree of cross-linking was controlled. Yang et al. ${ }^{37}$ studied the formation kinetics and reaction mechanism of the $\gamma$-glycidoxypropyltrimethoxysilane $(\gamma$ GPS) film on a metal surface. They demonstrated that the competition between two reactions, silanol-silanol condensation and silanol-metal hydroxyls $(\mathrm{MeOH})$ reaction, resulted in a complex film formation process. Effects of multi-reaction curing kinetics were also the subject of a number of other studies ${ }^{38,39}$.

Despite the extensive research on flat-surface coating processes, there has been no previous scientific study on the coating of three-dimensional objects, such as particles, with in-situ curing. Compared with flat surfaces, coating of particles involves complex mixing and heat transfer processes, which, when coupled with curing kinetics, makes the coating outcome much more challenging to control. In the oil and gas industry, the hot-melt process ${ }^{40}$ is often used for preparing resin-coated proppants, in which resin is mixed with the proppants at a temperature higher than 
its melting point and curing is induced in-situ through the addition of cross-linking agents ${ }^{41-43}$. Other techniques are also used, such as solution batch mixing method (where proppants are dispersed in a resin solution and later dried) and on-the-fly coating (where proppants, together with the resin and a surface active agent, are suspended in a stream of gelled aqueous carrier for continuous coating $)^{44,45}$. However, these methods are primarily applied for "onsite" coating (proppants are coated during the hydraulic fracturing process) and require the use of solvents. In this study, we select the more widely applicable hot-melt coating process and systematically investigate the effects of various operating parameters on the coating performance, which to the best of our knowledge has not been reported in the literature. The goal is to develop a low-cost and efficient method for polymer coating over solid particles. In addition to establishing the relationship between operating parameters and coating performance, the study also aims to provide insight into the intricate physical and chemical processes that underlie the coating process and determine its outcome. Although proppant coating is our main focus, the strategy demonstrated in this study can be generalized to a broad range of applications where particle coating with in-situ curing is desired.

\section{Experimental Section}

\subsection{Materials}

Proppants comprised of metal oxides, with a size ranging from $0.4 \mathrm{~mm}$ to $0.8 \mathrm{~mm}$ (between 20 and $40 \mathrm{mesh}$ ), and with assorted shapes (from near-spherical to angular) was used as received from Hatch Ltd. Durez 34358 novolac phenol-formaldehyde pastille resin was used as received from Durez Corporation. Hexamethylenetetramine (HMTA, $\geq 99.0 \%)$ and ammonium hydrogen difluoride $\left(\mathrm{NH}_{4} \mathrm{HF}_{2}, \geq 98.5 \%\right)$ were used as received from Sigma Aldrich. Hydrochloric acid ( $\mathrm{HCl}, 36.5 \%$ - 38.0\%) was used as received from Caledon Laboratories Ltd. Deionized water (DI water) was used for all solutions.

\subsection{Resin Coating Processes}

Performance of two coating processes was investigated. Schematics of the processes are shown in Figure 1. Both of them used the same experimental setup and followed similar procedures except that one kept the coating temperature constant (Figure 1a) whereas the other used a ramping temperature profile (Figure 1b). A batch size 
(a)

Dried proppants Resin

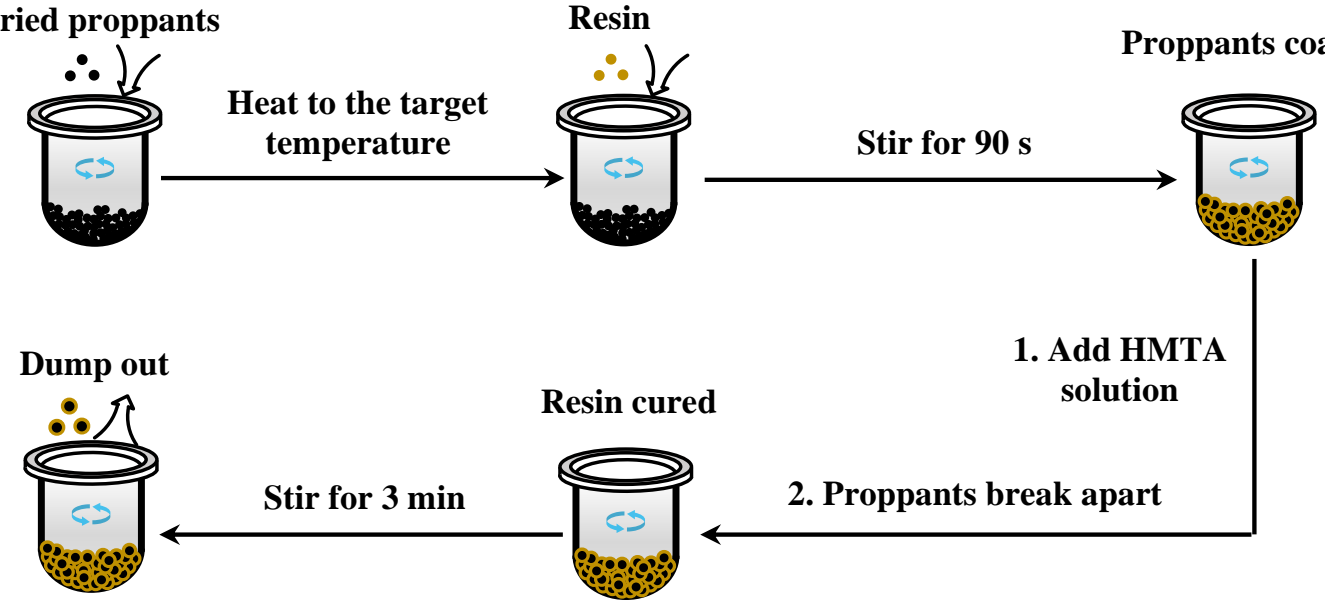

(b)

Dried proppants
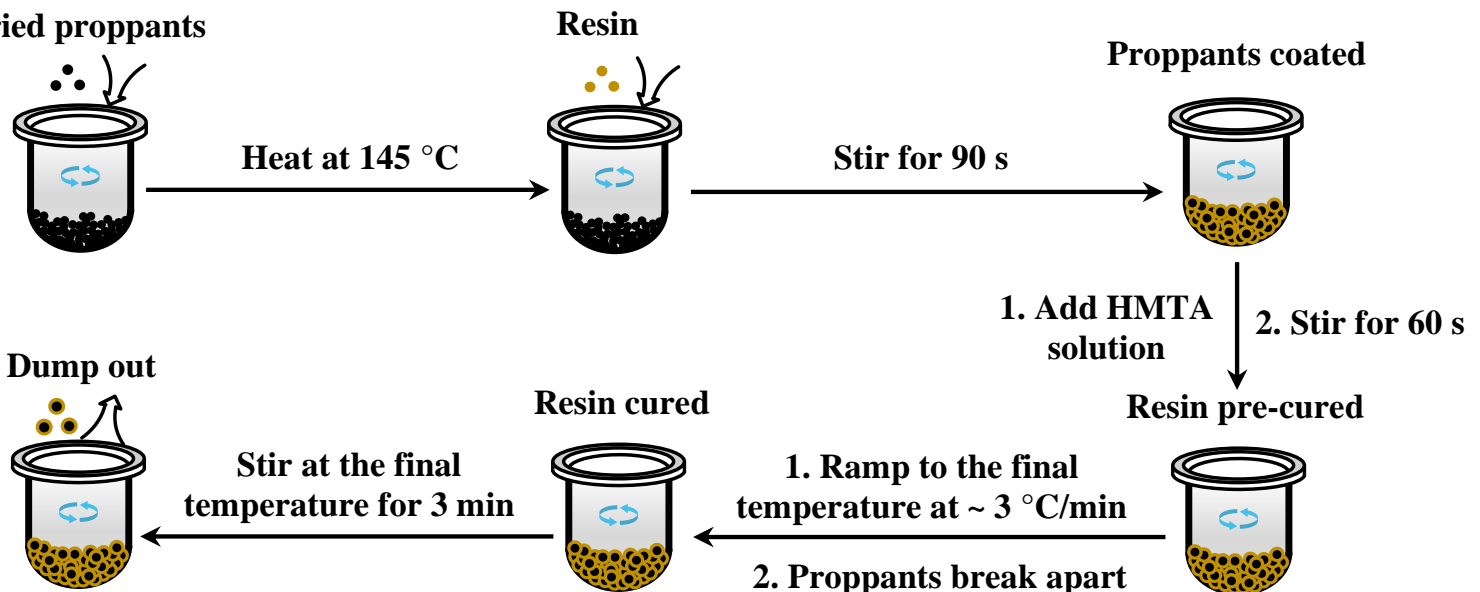

Resin cured

Resin pre-cured
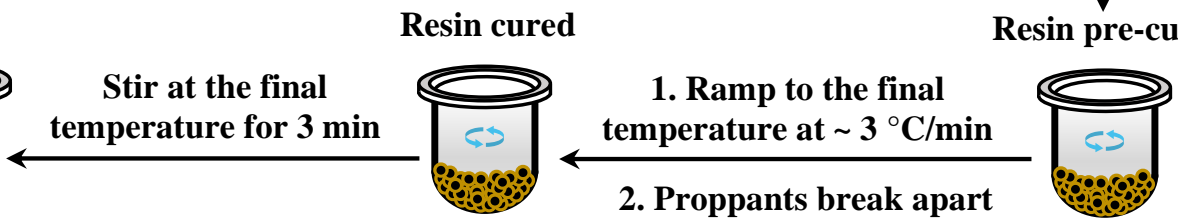

(c)

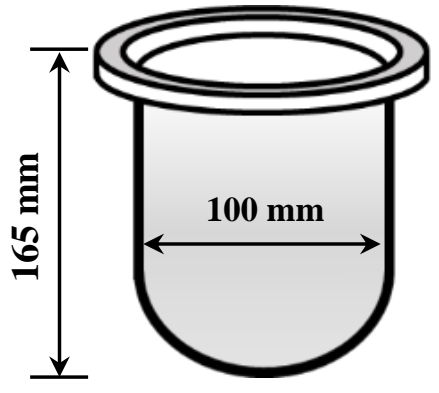

(d)

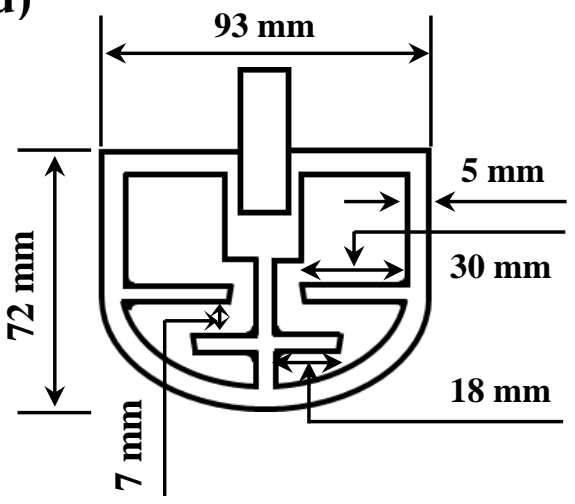

(e)

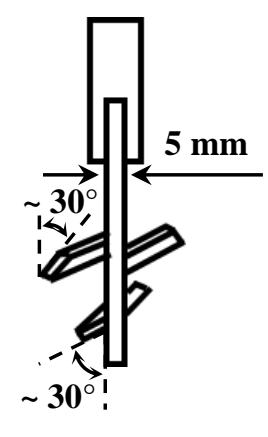

(f)

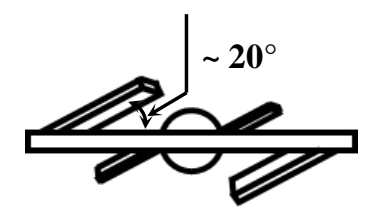

Figure 1 Schematics of the coating processes and apparatus: (a) constant temperature process, (b) ramping temperature process, (c) reactor vessel and the impeller design [(d) front view, (e) left view and (f) bottom view]. 

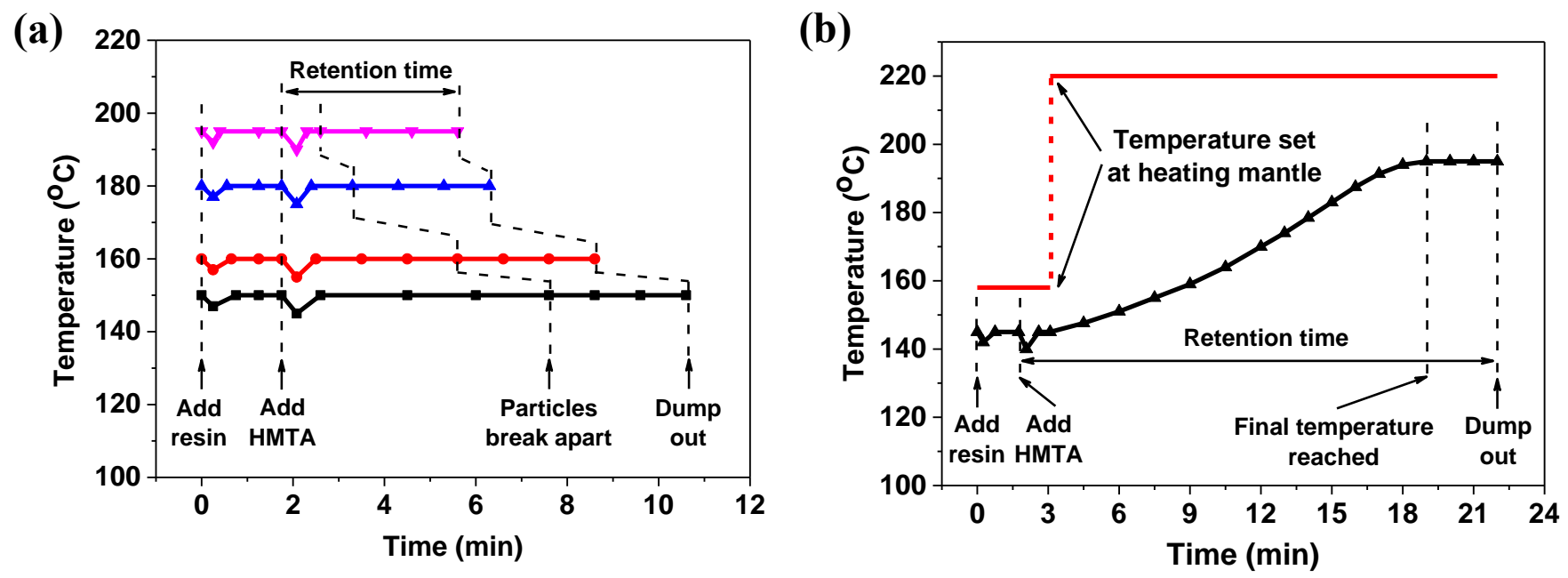

Figure 2 Temporal temperature profiles of the coating processes: (a) CT process $\left(150{ }^{\circ} \mathrm{C}, 160{ }^{\circ} \mathrm{C}, 180{ }^{\circ} \mathrm{C}\right.$, and $195^{\circ} \mathrm{C}$ ) and (b) RT process; symbols represent real-time measurements during typical processes.

of $100 \mathrm{~g}$ proppants was used for all coating experiments. The proppants were dried in an oven overnight before being transferred to a preheated reactor vessel (Figure 1c). The vessel was heated with a heating mantle and its temperature was measured by an infrared temperature gun. The samples were stirred with an impeller (Figure 1d 1f) throughout the process. In the constant temperature (CT) process (Figure 1a; corresponding temperature profiles are shown in Figure 2a), once the proppant temperature reaches the target value, resin pastilles (resin-toproppant weight ratio of $1.6 \%$ or $3.3 \%$ ) were added over $15 \mathrm{~s}$, which quickly melt after contacting with the hot proppant surface and led to a decrease in temperature of $\sim 3{ }^{\circ} \mathrm{C}$. Another $90 \mathrm{~s}$ was allowed for the temperature to stabilize and resin melt to distribute over the particles surface. HMTA solution (35\% w/w in DI water) was then added to cure the resins, causing the temperature to drop by $\sim 5^{\circ} \mathrm{C}$; a dry HMTA to resin weight ratio of $12 \%$ was used (higher HMTA dosage was tested with no significant influence on the results). The temperature was maintained at the target value for the rest of the process. As curing proceeded, the resin turned from a viscous fluid to a dry solid after which the coated particles began to break apart from one another. The products were stirred for additional 3 min (i.e. final holding stage) before they were discharged from the reactor and cooled down to the room temperature. A 16-mesh sieve was then used to screen the coated particles to remove the agglomerates. The ramping temperature (RT) process is similar except that the temperature started at $145^{\circ} \mathrm{C}$ and was gradually increased to a higher final temperature after HTMA was introduced (Figure 1b). As shown in Figure 2b, 1 min after the addition 
of HMTA, a step change is imposed on the temperature of the heating mantle, which is raised to $220{ }^{\circ} \mathrm{C}$ (higher than the target temperature in the vessel). It takes about 16 min for the system temperature, measured at the center of the vessel, to reach the target final value, after which the system is held at this temperature for an additional 3 min. Spatial temperature distribution is nearly uniform at different stages: we have compared the measurements at different radial positions and the variation $\left(<2{ }^{\circ} \mathrm{C}\right)$ is smaller than the equipment error. We define the retention time of the curing process as the time from HMTA addition to the end of the process. For the CT process, it varies with the system temperature --- from $\sim 3.5 \mathrm{~min}$ at $195{ }^{\circ} \mathrm{C}$ to $\sim 8.5 \mathrm{~min}$ at $150{ }^{\circ} \mathrm{C}$ : it takes longer time for the particles to break apart when temperature is lower. The retention time is much longer $(\sim 20 \mathrm{~min})$ for the RT process, which we will further discuss below, owing to the time required for the system to reach the target final temperature. Both processes do not require specialized equipment and can be readily scaled up for low-cost high-efficiency mass production. HMTA solution can be added either in droplets (using a pipette) or as a fine mist (using a spray bottle). Our experiments showed no noticeable difference in the resulting coating quality between the two methods.

Efficient stirring is crucial to avoid particle aggregation. Through repeated trials and errors, we have come to an impeller design (Figures 1d 1f) that essentially eliminates aggregation. Several features in this design were found to be particularly important. First, the impeller size matches the inner diameter of the vessel (Figure 1c), which eliminates the dead regions of mixing and prevents the particles from sticking to the wall. Second, the large hollow area on the blade surface allows particles to pass through and avoids particle aggregation to the impeller surface. Third, four horizontal slabs extend into the hollow, which increases the tangential shearing rate between particles in the bulk and prevents their aggregation. The slabs are twisted out of the plane (by $\sim 30^{\circ}$, see Figure 1e) to allow particles to slide over as the impellor turns. The stirring rate used here was 350 revolutions per minute (rpm); the corresponding shear rate generated in the granular mixture is estimated at $\sim 40 \mathrm{~s}^{-1}$, which was sufficient to efficiently mix the proppants with the resin and prevent particle-particle aggregation during the coating process. Further higher stirring rate will lead to the splashing of the particles. Under our current conditions, the amount of agglomerates was less than $1 \mathrm{wt} . \%$.

\subsection{DSC Measurements}


Differential scanning calorimeter (DSC) measurement was conducted to study the kinetics of the curing reaction between phenolic resin and HMTA using a Q20 DSC equipment (TA Instruments, DE, USA). To prepare the sample, $6.2 \mathrm{mg}$ of HMTA and milled resin, with an HMTA-to-resin weight ratio of 12\%, was loaded into an aluminum crucible and dried in a desiccator before measurement. Temperature scan was performed at a heating rate of $10^{\circ} \mathrm{C} / \mathrm{min}$. Nitrogen atmosphere was used with a gas flux rate of $50 \mathrm{~mL} / \mathrm{min}$.

\subsection{TGA Measurements}

Thermo-gravimetric analysis (TGA) was performed on coated proppants to determine the amount of resin applied onto the proppant surface. TGA was performed with a Q5000 IR TA instrument (TA Instruments, DE, USA) at a heating rate of $15{ }^{\circ} \mathrm{C} / \mathrm{min}$ under air environment. Each proppant sample was held at $102{ }^{\circ} \mathrm{C}$ for 5 minutes to ensure removal of water before proceeding to higher temperatures.

\subsection{SEM Imaging}

A Tescan Vega II LSU scanning electron microscopy (SEM) (Tescan USA Inc., PA, USA), operating at 15.0 kV, was used to inspect the surface morphology of the uncoated and resin coated proppants. Samples were fixed onto aluminum specimen stubs using carbon paints and coated with a gold layer by means of sputter coating in a Polaron E5100 coating unit (Polaron Instruments Inc., Watford, England) prior to SEM imaging.

\subsection{Resin Coating Performance Characterization}

Two characterization methods were used to quantify resin coating performance in the context of fracking application:

(1) the acid solubility test measures the effectiveness of the resin coating in shielding the proppants from chemical leaching and (2) the crush resistance test measures its capability in maintaining the structural integrity of proppants under high pressure. For both methods, explained in detail below, industrial standard protocols ${ }^{46}$ are followed. Despite their roots in the oil and gas industry, outcomes of these tests directly reflect coating-layer properties of general interest, such as its surface coverage (both tests), barrier property (acid solubility test) and mechanical strength (crush resistance test). 


\subsubsection{Acid Solubility Test}

The acid solubility test measures the amount of weight loss in proppants after their exposure to a strong acid solution. Uncoated proppants are chemically unstable in acidic environments, for which the resin coating provides a protective layer. Performance in this test thus directly depends on the coating-layer coverage and its barrier property, i.e., resistance to acid permeation, which depends on the crosslinking density ${ }^{47}$. We follow the procedure given by the American Petroleum Institute Recommended Practice 19C (API RP 19C) ${ }^{46}$.

An acid solution containing $12 \% \mathrm{HCl}$ and $3 \% \mathrm{HF}$ is prepared by mixing the appropriate amounts of solid $\mathrm{NH}_{4} \mathrm{HF}_{2}$, $37 \% \mathrm{HCl}$ solution and DI water. For the solubility test, $5 \mathrm{~g}$ of proppant samples were dried at $105{ }^{\circ} \mathrm{C}$ and then cooled down to the room temperature. The samples were added into a plastic beaker containing $100 \mathrm{ml}$ of the acid solution. The beaker was then sealed to prevent the acid from evaporation and placed in a $66{ }^{\circ} \mathrm{C}$ water bath for 30 minutes without stirring. The acid solution was removed after the test via vacuum filtration and the retained solids were washed with $20 \mathrm{ml}$ of DI water for three times. The solid sample was then dried at $105{ }^{\circ} \mathrm{C}$ until its weight levels off. The acid solubility was measured by the percentage mass loss of the sample compared with its initial weight.

\subsubsection{Crush Resistance Test}

The crush test measures the amount of crushed fines generated after a high pressure is applied onto the proppants. This crush resistance property depends on the coating-layer coverage and the mechanical strength of the coatings which is affected by the degree of crosslinking as well ${ }^{36,48}$. The procedure for this test also follows the recommendation in API RP $19 \mathrm{C}^{46}$.

The proppants were sieved using a 20/40 mesh sieve stack, comprising of a 20-mesh brass sieve on the top, a 40mesh brass sieve in the middle, and a pan at the bottom. A test cell and piston were prepared in accordance to the recommendations outlined in API RP 19C. The sample, which weighs at $35.1 \mathrm{~g}$, was loaded into the test cell and the piston was then gently placed on top of the sample. The sample surface was smoothed by rotating the piston $180^{\circ}$ clockwise once. The test cell together with the piston was placed on a hydraulic load frame. A load was exerted 
onto the test cell and piston at a rate of 2000 pounds per square inch (psi) per minute until a final stress of 15,000 psi was reached. The final stress was held for 2 minutes before release. The crushed sample was sieved using the 20/40 mesh sieve stack. The material passing the 40-mesh sieve and that ended on the pan was weighed. Crush resistance was reported as the percentage of the original sample mass that ended up on the pan.

\section{Results and Discussion}

\subsection{Resin Curing Reaction}
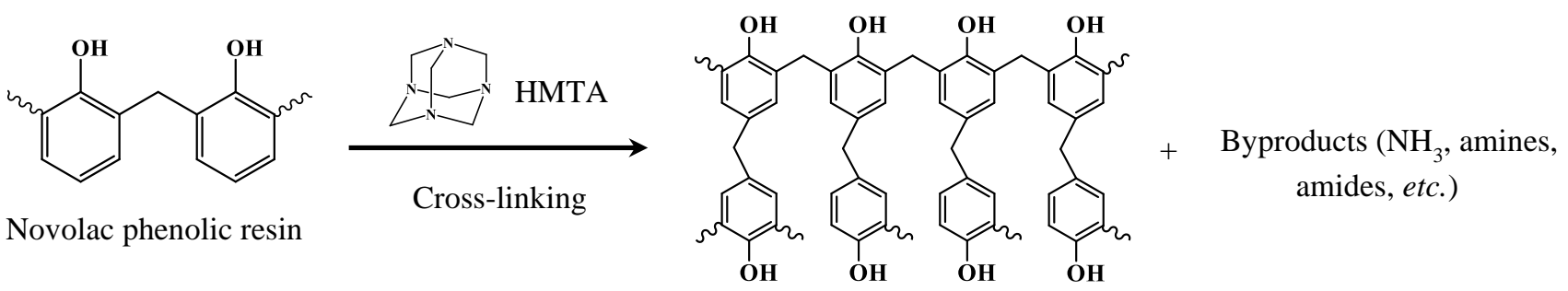

Figure 3 Schematic illustration of the curing reaction between phenolic resin and HMTA.

The curing reaction between the novolac phenolic resin (uncrosslinked precursors) and hexamethylenetetramine (HMTA) is highly complex. Its mechanism is not fully understood ${ }^{49-52}$, but can be generically depicted by Figure

3. It is believed to consist of two stages: various intermediates, mainly benzoxazines and benzylamines, are first formed, before they are further crosslinked into a network ${ }^{49}$.

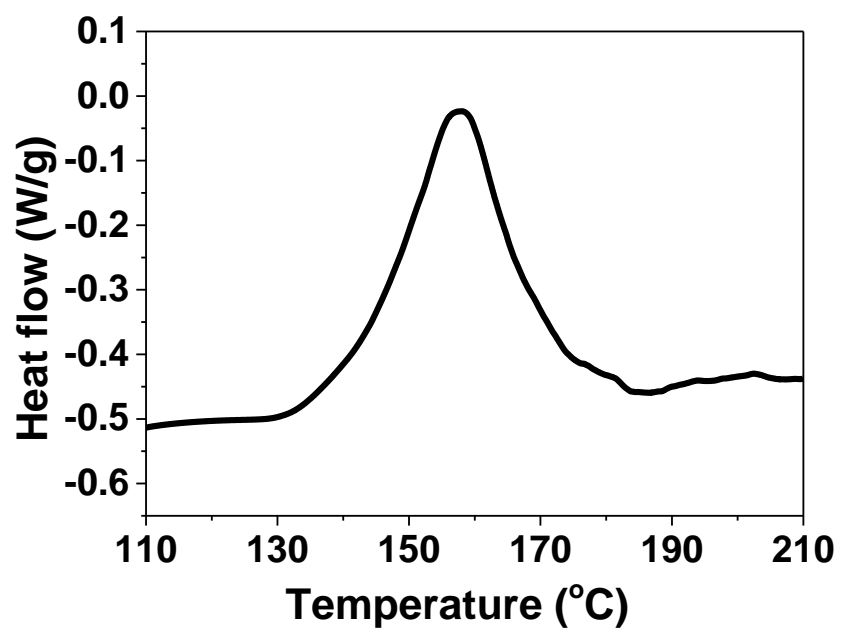

Figure 4 Dynamic DSC curve of an HMTA/resin mixture at a heating rate of $10{ }^{\circ} \mathrm{C} / \mathrm{min}$. 
DSC was utilized to study the curing kinetics of phenolic resin and HMTA. As shown in Figure 4, a single peak for heat release during the curing reaction extends approximately from $140{ }^{\circ} \mathrm{C}$ to $180{ }^{\circ} \mathrm{C}$. The curve shifts slightly with the heating rate: e.g., reducing the heating rate to $5{ }^{\circ} \mathrm{C} / \mathrm{min}$ will move the peak to the left by about $5{ }^{\circ} \mathrm{C}$. Meanwhile, this temperature range is also very close to literature values ${ }^{53}$. Therefore, we take $140{ }^{\circ} \mathrm{C} \sim 180{ }^{\circ} \mathrm{C}$ as the approximate temperature range of the curing reaction when selecting our coating temperatures.

\subsection{Resin Coating Process}

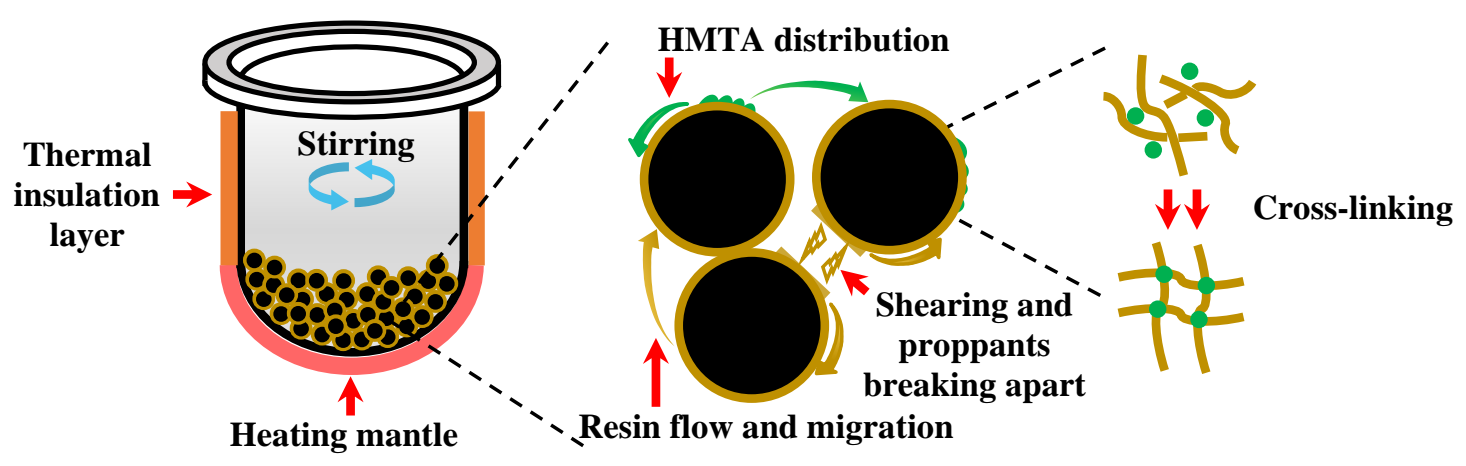

Figure 5 Schematic illustration of the coating process.

The underlying physical and chemical processes are depicted in Figure 5. After resin is added into the vessel, it is melted by the high temperature and is thus able to flow and mix with the preheated particles. High-speed stirring facilitates the distribution of the melt resin over the particle surface as well as among different particles. It induces fast shear motion between particles which evens the melt distribution and prevents particle aggregation. As soon as the HMTA solution is added and makes contact with the particles, water quickly evaporates under the high temperature. Although HMTA can be dispersed among particles by mechanical stirring, molecular diffusion within the coating layers is still needed for a uniform crosslinking density. As crosslinks are formed, the resin becomes increasingly viscous and eventually solidifies with the formation of the polymer network, which not only freezes the resin flow but also drastically slows down the HMTA diffusion. In addition, if the crosslinking rate is faster than the dynamic contact between particle surfaces, bonds will be formed bridging the coating layers of different particles, resulting in particle agglomerates. Other processes such as heat-induced coating damages may also occur due to the high processing temperature. These simultaneous processes, including the re-distribution and diffusion 
of HMTA, curing reaction, particle collision and break-up, and heat-induced coating damages, compete with one other and the coating outcome is determined by their dynamic and complex coupling. How to control the operating parameters for an optimized competition profile of these processes, or best coating outcome, is the central challenge of the study.

\subsection{TGA Investigation}
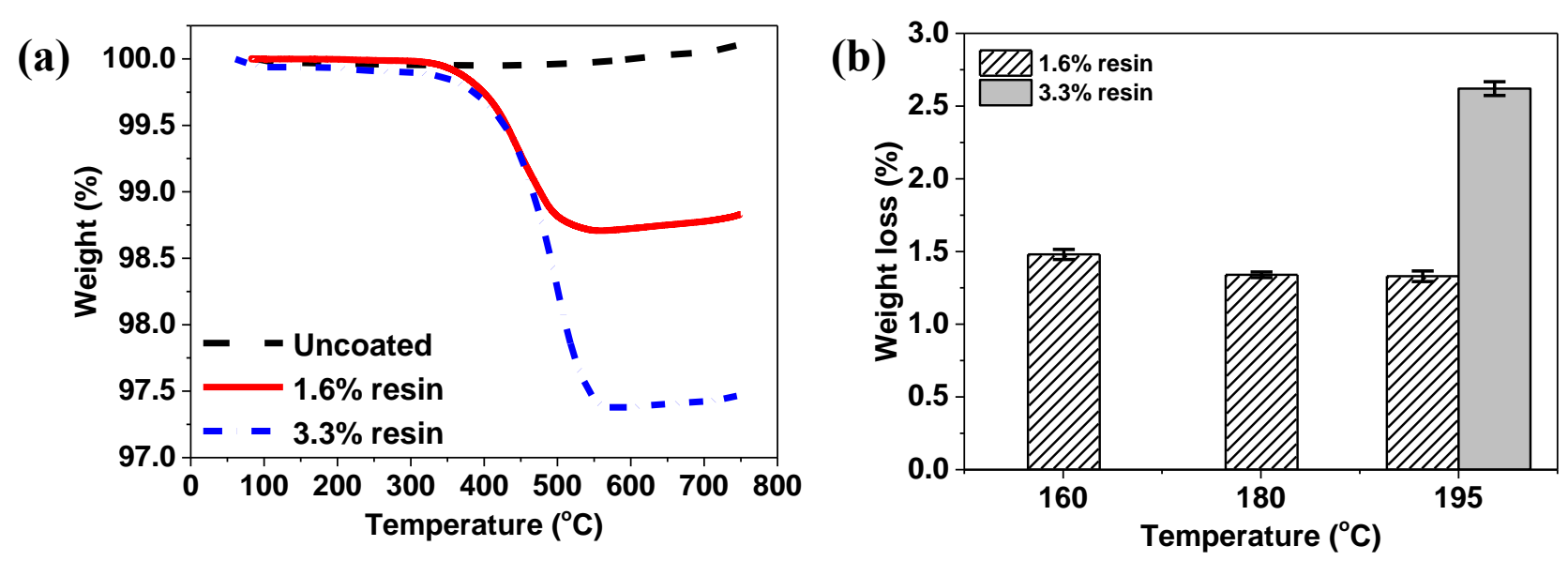

Figure 6 (a) TGA curves for uncoated and coated proppants with different resin-to-proppant ratios and (b) percentage weight loss of coated particles in TGA for different conditions.

TGA tests were performed on the coated proppants to determine the amount of resin successfully applied onto the proppant surface. TGA curves for two coated samples, with resin-to-proppant ratios of $1.6 \%$ and $3.3 \%$ (hereinafter, resin-to-proppant ratios are measured by the weight ratio between the amount of resin added and the amount of proppants to be coated) and prepared with a CT process at $\mathrm{T}=195^{\circ} \mathrm{C}$, are shown in Figure 6a along with that of uncoated proppants. Resin decomposition mostly occurs in the range of $350 \sim 550{ }^{\circ} \mathrm{C}$ and the total weight loss reflects the weight of resin coatings. The percentage weight loss after TGA, measured by the ratio of weight loss to the weight of uncoated proppant substrates, is plotted in Figure $\mathbf{6 b}$ (three different temperatures for the resin-toproppant ratio of $1.6 \%$ and $195{ }^{\circ} \mathrm{C}$ for $3.3 \%$ ). In all cases, the weight of resin coatings is only slightly lower than the total amount of resin initially added, and there is no substantial dependence on variations in process conditions. This observation is also valid for other coating conditions not shown here. As such we are confident that most resin 
has been successfully coated and retained on the proppant surface and for the same resin-to-proppant ratio, the amount of resin coatings is similar for different process conditions.

\subsection{Effects of Resin Dosage}
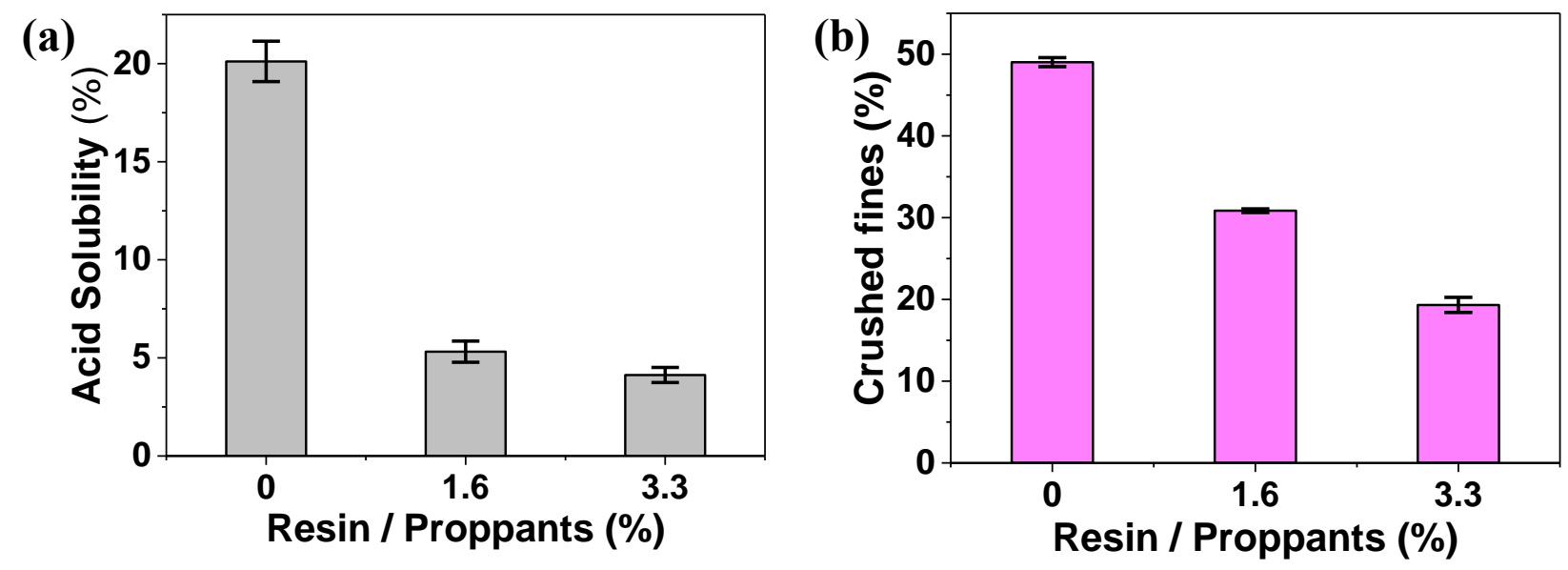

Figure 7 Influence of the resin-to-proppant ratio on the acid solubility and crush resistance of the coated proppants prepared by the $\mathrm{CT}$ process at $195^{\circ} \mathrm{C}$.

Effects of resin dosage on coating properties were investigated for two resin-to-proppant weight ratios (1.6\% and 3.3\%) and shown in Figure 7. Compared with the uncoated proppants (0\%), improvements brought by the resin coating layer are dramatic: there is a fourfold reduction in acid solubility for both resin-to-proppant ratios and crush weight loss is cut by more than half at least in the higher resin-to-proppant ratio case. The success of resin coatings in improving proppant performance is thus evident. The cured resin layer makes it more difficult for the acid molecules to penetrate and erode the particles. The crush protection function of the resin coating is multifold. In addition to the direct enhancement of the mechanical strength of proppants, the coating can also encapsulate the fines in the event of proppant crushing and thus maintain the structural integrity of the grain ${ }^{5}$. Furthermore, even for the ruptured particles, the resin can still act as a glue that holds the fines together in larger pieces. This last effect is clearly seen by comparing the photographs of the crushed fines (which passed through a 40-mesh sieve) from uncoated and coated proppants with 1.6\% resin, as shown in Figure 8. Smaller fines were observed for the uncoated proppant compared to the resin-coated proppant. 
(a)

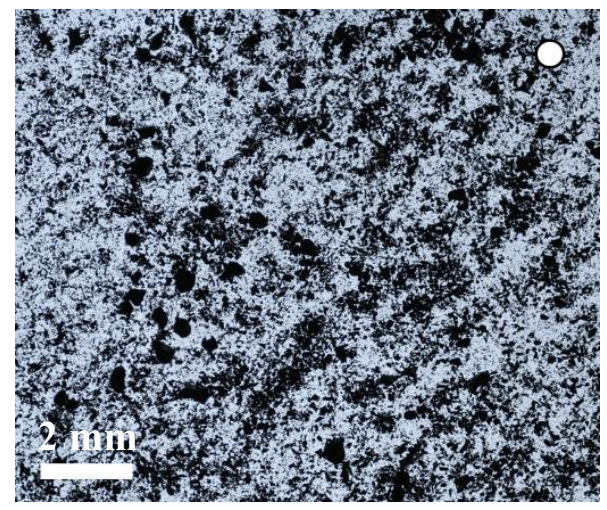

(b)

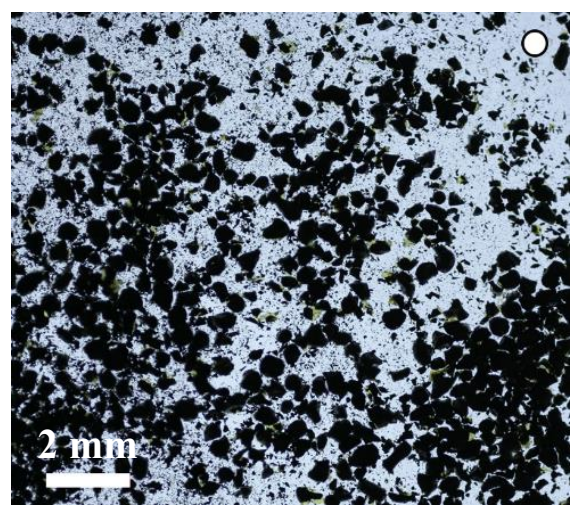

Figure 8 Images of the crushed fines from (a) uncoated proppants and (b) resin-coated proppants. White circles at the top-right corner show a typical proppant size of $0.6 \mathrm{~mm}$.

The marginal benefit of increasing the resin-to-proppant ratio from $1.6 \%$ to $3.3 \%$ is noticeable but limited: the percentage weight loss in the crush test is reduced by a further $10 \%$, but improvement in acid resistance is not significant. A larger amount of resin on the proppant surface increases the coating thickness and strength, thereby providing better tolerance to high pressure, whereas a thin layer of cured resin seems to be sufficient for acid protection. Since resin usage is a major contributor to the overall cost of the process, we focus the rest of the study on optimizing the coating performance with lesser resin (i.e. resin-to-proppant ratio of $1.6 \%$ ) but by changing coating process parameters. With the cost of phenolic resin estimated at $\sim 2$ U.S. dollars per $\mathrm{kg}$, this dosage is going to increase the manufacturing cost by $~ 32$ U.S. dollars per tonne of uncoated proppants.

\subsection{Effects of Process Temperature Profile}

\subsubsection{Constant Temperature (CT) Process}

We started by holding the temperature constant for the entire process (Figure 1a) and tested several different temperature levels. SEM images of these samples are shown in Figure 9. From the surface images (Figures 9a 9d), it is clear that a constant high process temperature (e.g. $195^{\circ} \mathrm{C}$ ) results in a rough surface (with more bumps), while a comparatively low temperature (e.g. $150{ }^{\circ} \mathrm{C}$ ) gives better surface smoothness. Cross-sectional images in Figures 9e $\sim 9 \mathrm{~h}$ were taken from manually crushed proppant particles, in which consistent coated layers of about $3 \sim 6 \mathrm{~nm}$ are clearly visible. We have also tested the effects of the HMTA addition method and found that surface 

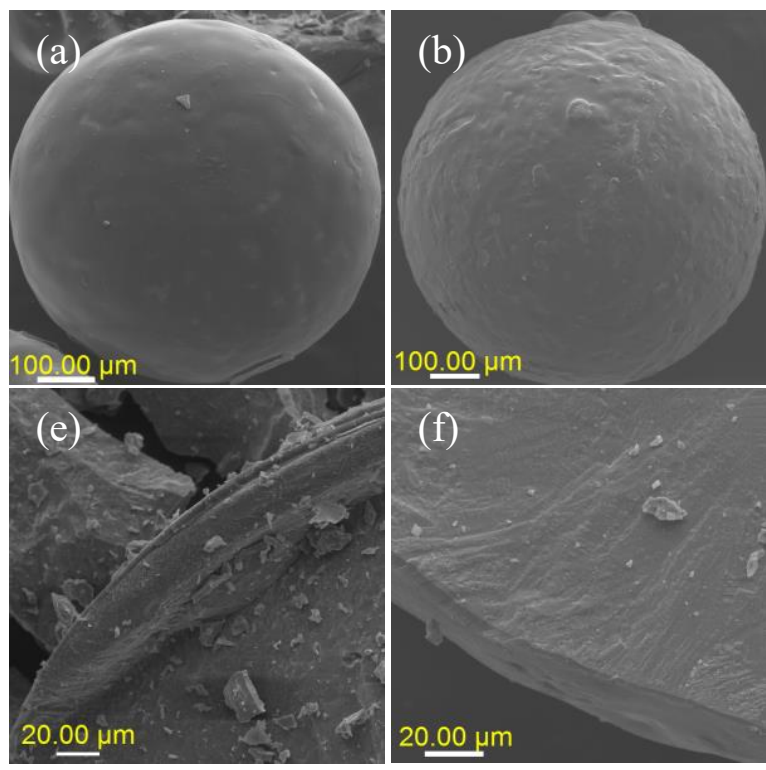
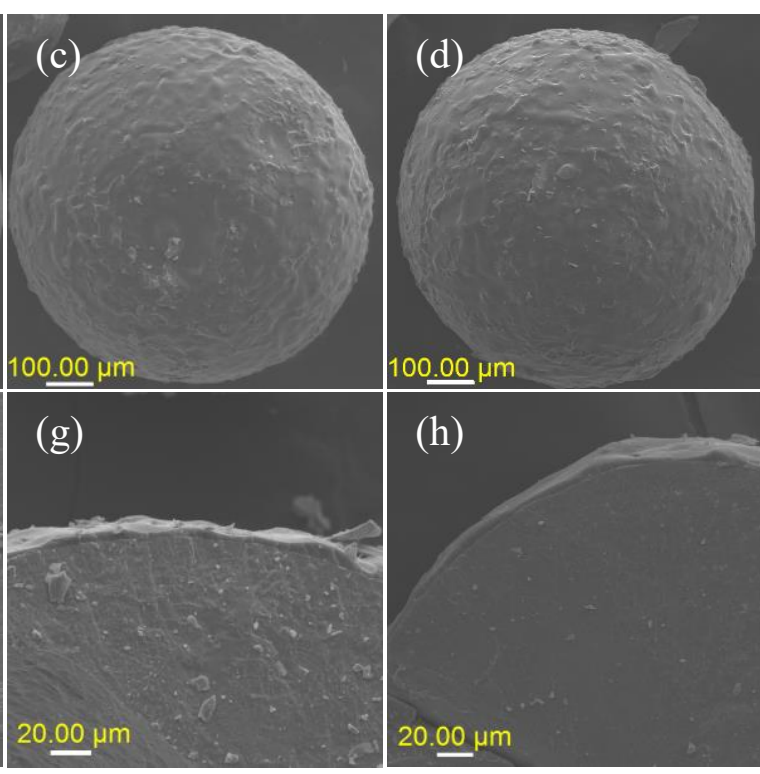

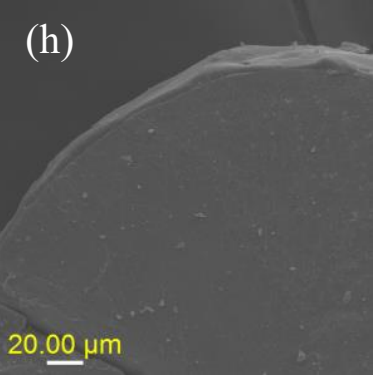

Figure 9 SEM images of the resin-coated proppants and their cross-sectional images prepared by the CT process at (a) \& (e) $150{ }^{\circ} \mathrm{C}$, (b) \& (f) $160{ }^{\circ} \mathrm{C}$, (c) \& (g) $180{ }^{\circ} \mathrm{C}$ and (d) \& (h) $195{ }^{\circ} \mathrm{C}$.

morphology of the obtained coating layer is indistinguishable whether the HMTA solution was added as droplets or as a fine mist. Although spraying gives a more uniform macroscopic distribution among particles, as discussed below, it is the mixing at the molecular level, which relies on diffusion, that determines the surface quality.

When drips of HMTA solution hit the resin surface, local spots with high HMTA concentration are formed. At high temperature the high reaction rate quickly leads to the gelation of these spots before HMTA is dispersed to broader regions, while the adjacent resin remains at the melt state. Limited mobility and slower diffusion in these gel spots keep HMTA distribution localized, whereas the surrounding resin melt can still flow inwards to react with HMTA and further strengthen the gelled regions, thereby amplifying the surface inhomogeneity. Meanwhile, a low temperature has a lower reaction rate, thereby allowing more time for HMTA molecules to diffuse across the coating layer and migrate to different particles. Even distribution of the cross-linking agent ensures that the reaction proceeds uniformly across all regions. Since resin flow and HMTA distribution are able to reach a dynamic equilibrium faster than the curing reaction, the whole resin layers reaches the gel point at about the same time, leading to a smooth and homogeneous surface morphology. 

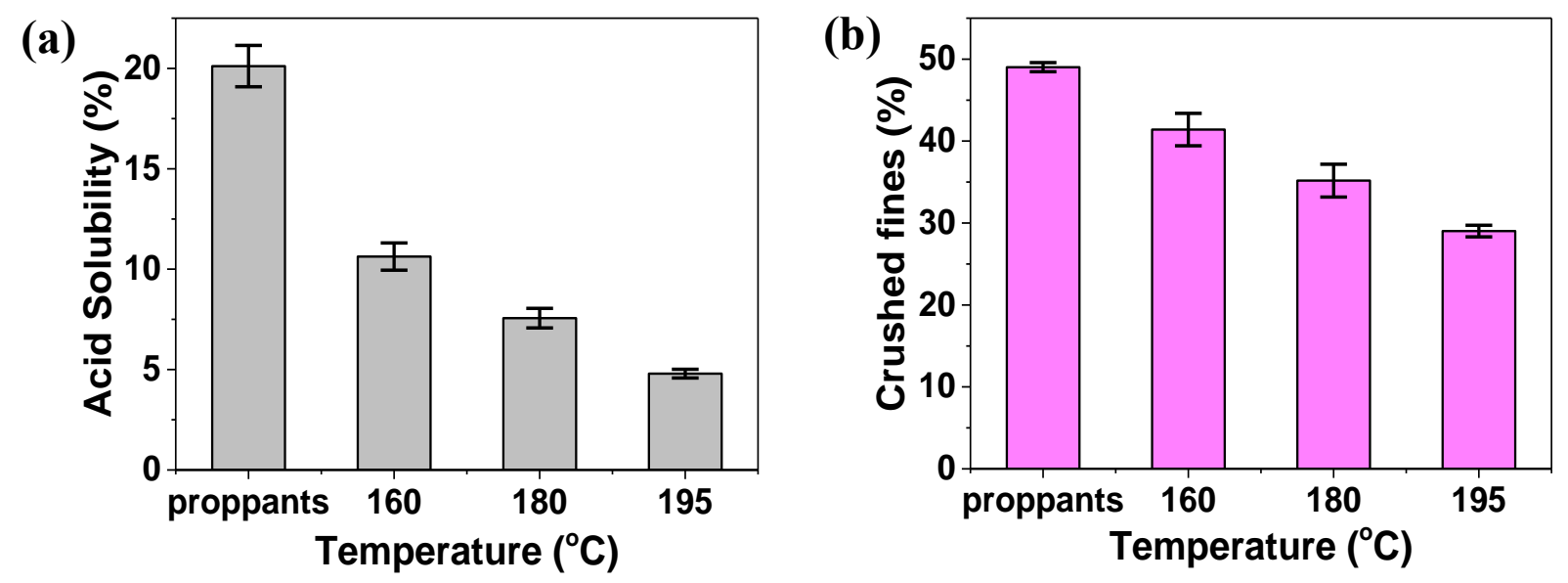

Figure 10 Acid solubility and crush resistance of the uncoated and resin-coated proppants prepared by the CT process at $160^{\circ} \mathrm{C}, 180{ }^{\circ} \mathrm{C}$ and $195^{\circ} \mathrm{C}$.

For resin coating layers with the same microscopic coating quality, a uniform cured resin coating surface with few flaws should provide superior acid solubility and crush resistance properties than an inhomogeneous one. Flaws, such as regions with limited resin (thinner coating), may encourage preferential acid attack in the acid solubility test and which may act as stress points resulting in failure in the crush resistance test.

This prediction is however opposite to the coating performance results shown in Figure 10, where both acid and crush resistances improve with the temperature despite the worsening surface morphology. It is thus clear that the microscopic structure of the coating layer has also changed with the process temperature. Indeed, as seen from our DSC analysis in Figure 4, the curing reaction occurs over the range of approximately $140{ }^{\circ} \mathrm{C}$ to $180{ }^{\circ} \mathrm{C}$. A temperature as low as $150{ }^{\circ} \mathrm{C}$ or $160{ }^{\circ} \mathrm{C}$ is likely not sufficient for all crosslinking bonds to be formed, leading to lower crosslinking density. The resulting coating layers are likely more porous, permeable to acid molecules, and susceptible to mechanical damage. For the lowest process temperature tested $\left(150{ }^{\circ} \mathrm{C}\right.$; not shown here), we have also extended the final holding temperature from $3 \mathrm{~min}$ to $20 \mathrm{~min}$. Coating performance does not improve with the longer holding time, confirming that our current retention time is sufficient for highest coating quality at the temperature (the coating actually deteriorates with prolonged heating, which we will discuss below). Meanwhile, at a high process temperature of $195^{\circ} \mathrm{C}$, crosslinking density is close to its maximum. Improved microscopic density at higher temperatures overcomes the non-uniformity in the film thickness, yielding a cured resin with improved 
acid resistance performance and mechanical strength. This opposite temperature dependence between surface smoothness and coating performance prompted us to further explore the temperature profile for an optimized coating outcome.

\subsubsection{Ramping Temperature (RT) Process}
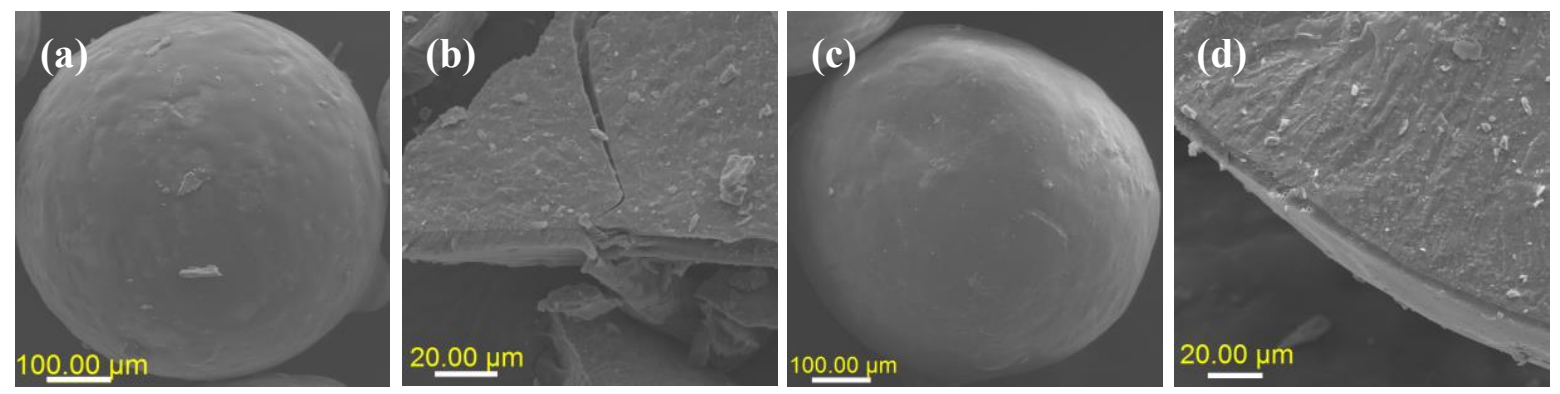

Figure 11 SEM images of resin-coated proppants and their cross-sections prepared by the RT process with the initial/final temperatures of (a) \& (b) $145 / 175{ }^{\circ} \mathrm{C}$ and (c) \& (d) $145 / 195{ }^{\circ} \mathrm{C}$.

As discussed in Section 3.2, the hot-melt coating method involves complex coupling between multiple physical and chemical processes. Many of them, including the reaction kinetics, HMTA diffusion and resin rheology, depend strongly on temperature. Adjusting the temperature profile of the process is thus the most delicate yet most powerful means for the control and optimization of the coating process. For the CT process discussed above, lower temperature gives smooth coating surface, whereas higher temperature is required to complete the cross-linking reaction. We thus tested a new process (Figure 1b) where the temperature starts low to avoid fast initial gelation and allow sufficient time for the molecular mixing of HMTA in the resin layer. After a smooth surface is formed and partially cured, the temperature is gradually ramped up to bring the curing reaction to completion for a high final crosslinking density. The initial temperature we chose is $145^{\circ} \mathrm{C}$, which is close to the lower end of the range identified from DSC (Figure 4), and different final temperatures $\left(175^{\circ} \mathrm{C}\right.$ and $\left.195{ }^{\circ} \mathrm{C}\right)$ were tested. These two temperature profiles will be denoted by $145 / 175^{\circ} \mathrm{C}$ and $145 / 195{ }^{\circ} \mathrm{C}$, respectively. Figure 11 shows the SEM images of resin-coated particles prepared using this ramping temperature process. The cured resin surface morphology for both cases, shown in Figure 11a and 11c, appeared smooth and homogeneous and were comparable to the surface 
morphology obtained from the CT process at a low temperature of $150^{\circ} \mathrm{C}$ (Figure 9a). Cross-sectional images in Figure 11b and 11d indicated uniform cured resin layers of about $6 \mathrm{~nm}$.

Figure 12 shows the properties of resin-coated proppants prepared by the RT process with final temperatures of $175^{\circ} \mathrm{C}$ and $195^{\circ} \mathrm{C}$, compared with those of the $\mathrm{CT}$ process at $195^{\circ} \mathrm{C}$. It is clear that higher final temperature results in better acid and crush resistance of the coated particles, which can be attributed to the higher cross-linking degree of the coating layer. This is also consistent with the trend observed in the CT process described above. However, comparing the results of the $145 / 195{ }^{\circ} \mathrm{C}$ and $195^{\circ} \mathrm{C}$ cases, it is interesting to see that the coated proppants prepared at a constant temperature of $195{ }^{\circ} \mathrm{C}$ exhibit slightly better overall performance despite its inferior surface quality. Specifically, its acid resistance is noticeably better than that of the RT process, whereas for the crush test, results from the two processes are at the same level. Considering that the coating layer from the RT process is clearly more uniform and smoother and a final temperature of $195^{\circ} \mathrm{C}$ should ensure a similar conversion as the CT process (at the same temperature), it is expected that the outcome of the RT process should be at least at the same level of the CT one. However, one factor that has not yet been considered is the difference in the retention time between the two processes (see Figure 2): the RT process $\left(145 / 195^{\circ} \mathrm{C}\right.$ ) takes about $20 \mathrm{~min}$ after curing is initiated whereas for the CT process $\left(195^{\circ} \mathrm{C}\right)$ it is only about $3.5 \mathrm{~min}$. Longer time is needed in the former case to raise the temperature across the vessel. As discussed above, film thickness and microscopic structures are the two major factors

(a)

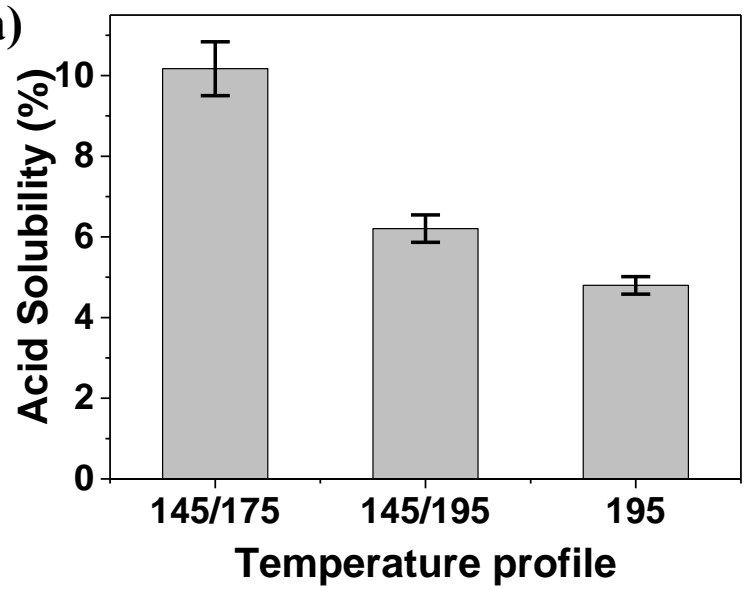

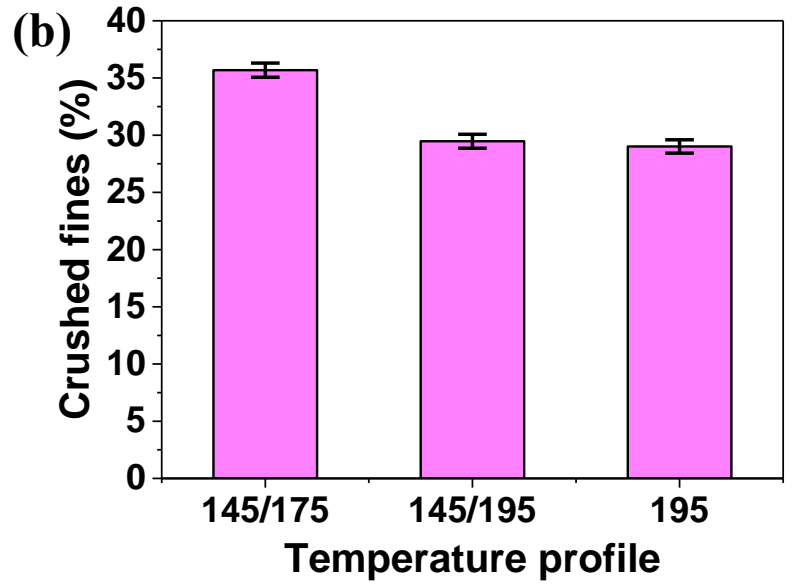

Figure 12 Properties of resin-coated proppants prepared by the RT process with the initial/final temperature of $145 / 175{ }^{\circ} \mathrm{C}$ and $145 / 195{ }^{\circ} \mathrm{C}$, compared with the CT process case at $195{ }^{\circ} \mathrm{C}$. 
determining coating performance. Despite the more uniform thickness, prolonged heating in the RT process may damage the latter and lead to deterioration in coating performance.

To test this hypothesis, different processing durations were tested. Using the CT process at $180^{\circ} \mathrm{C}$, HMTA was added to the reactor to initiate curing, which generally took $\sim 1 \mathrm{~min}$ (curing was signified by resin coated proppants breaking apart and no longer sticking to each other). We then varied the duration that the resin coated proppants were held in the reactor before discharging, that is, the additional time for heating and stirring after proppant breakapart (defined as holding time, the standard choice so far is $3 \mathrm{~min}$ ). Holding times of $0 \mathrm{~min}, 3 \mathrm{~min}, 10 \mathrm{~min}$, and 20 min were investigated. The performance of the resulting resin-coated proppant was shown in Figure 13. Acid resistance (Figure 13a) clearly deteriorates with heating time and the effect becomes obvious for a holding time of 10 min: note that this is still shorter than the heating time in the RT process. Worsening acid resistance indicates a more porous microscopic structure in the resin, likely as a result of chemical bond breakages caused by the prolonged heating. Impact on the crush resistance is more subtle (Figure 13b): there seems to be a slight initial decrease (between $0 \mathrm{~min}$ to $3 \mathrm{~min}$ ) in crush weight loss but the measurement soon plateaus. Results from this test are consistent with observations in Figure 12 where the RT process leads to slightly worse acid resistance but its crush test result is comparable with the CT process. It thus confirms the impact of total heating time on the coating performance. Since how fast we can ramp up the temperature is eventually limited by the heat transfer rate of the
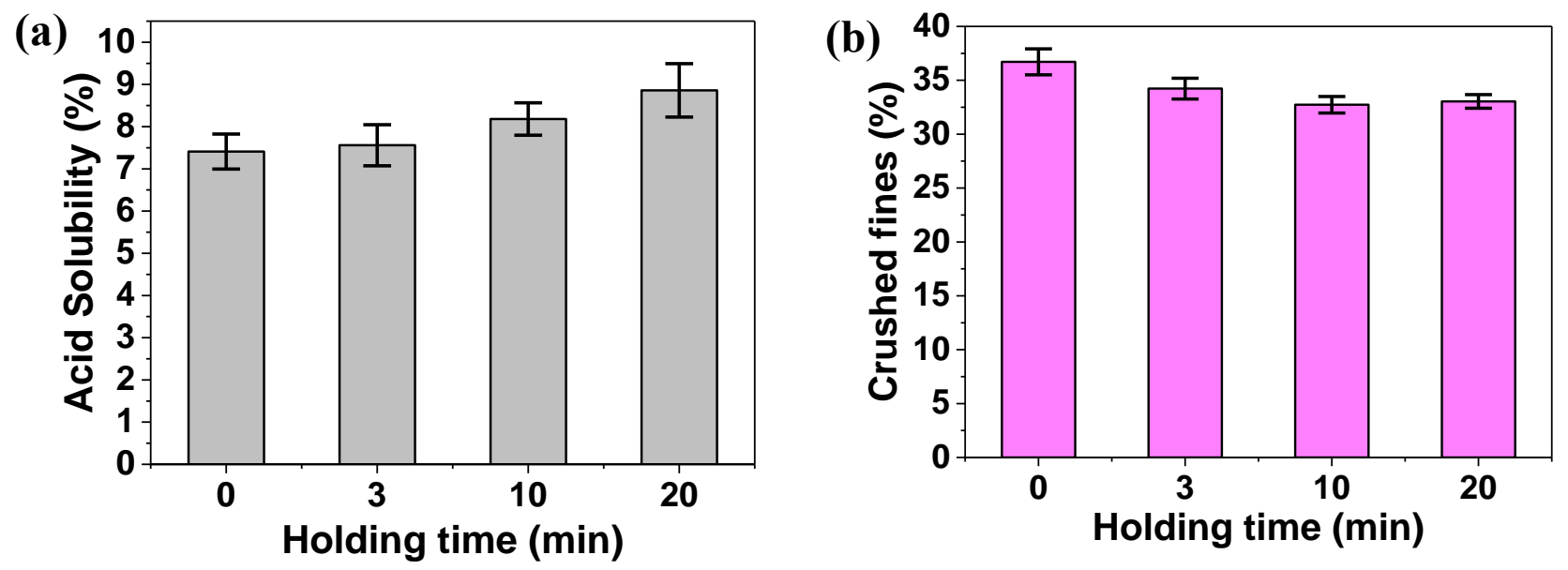

Figure 13 Effects of the final holding time on the performance of resin-coated proppants prepared by the $\mathrm{CT}$ process at $180^{\circ} \mathrm{C}$. 
setup, this limitation is inevitable for the RT process and will only get worse when the process is scaled up. As such, we conclude that as far as proppant performance is concerned, a CT process with high temperature $\left(195{ }^{\circ} \mathrm{C}\right)$ is optimal. The RT process only becomes a viable option when surface morphology is an important consideration.

\subsection{Effects of Particle Shape}

Having complete surface coverage is a prerequisite for coating layer effectiveness. Flaws, such as regions not sufficiently covered by resin or those where the resin is not cured, undermine the proppant performance. Spherical particles are more likely to receive a full coverage of uniform coatings for their symmetry. Irregularly-shaped particles, on the other hand, are more prone to coating defects and non-uniformity, owing to the difficulty of achieving even resin/HMTA distribution thereon. Proppants are often commercially available as mixtures of particles with assorted shapes. To weigh the improvement of selecting spherical proppants for coating against its additional cost, we use a spiral separator to sort out the spherical proppants from irregular ones. SEM images of the proppants with these different shapes are shown in Figure 14. Resin coatings were applied by the RT process with a final temperature of $195^{\circ} \mathrm{C}$. Coating performance of these samples are compared with one another and shown along with that of as-received proppants in Figure 15. Interestingly, the resin-coated spherical proppants show significantly better acid resistance while no noticeable change is observed in the crush resistance result. This suggests that even for irregular proppants the surface coverage and coating strength are sufficient for all three cases to provide crush protection. Differences in coating quality for the three particle geometries are likely in the surface uniformity, quantity of defects and cross-linking density, to which the acid solubility result is more sensitive.
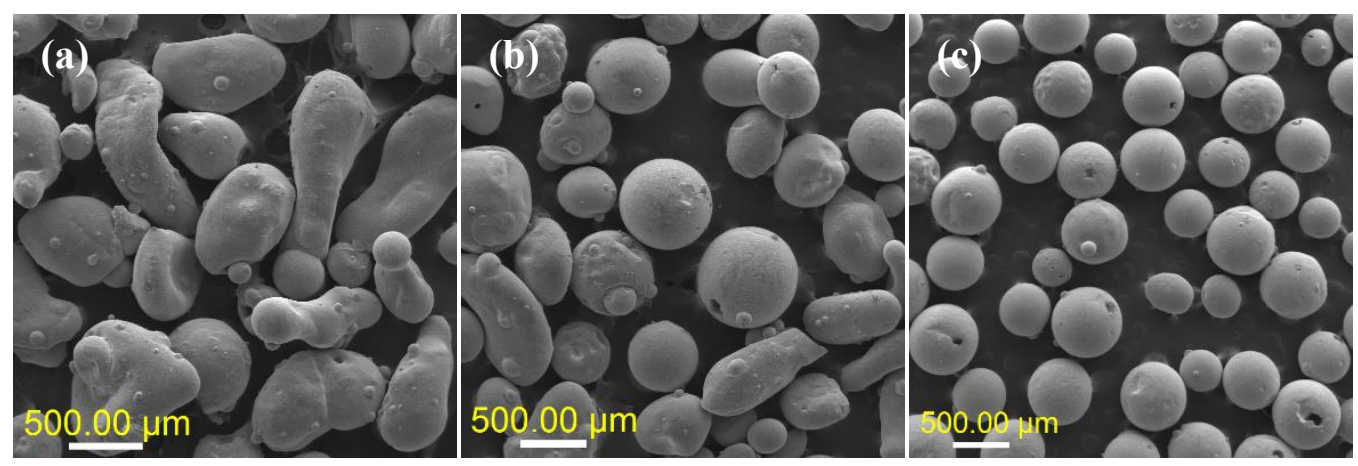

Figure 14 SEM images of the proppants with different shapes: (a) irregular; (b) as-received and (c) spherical. 

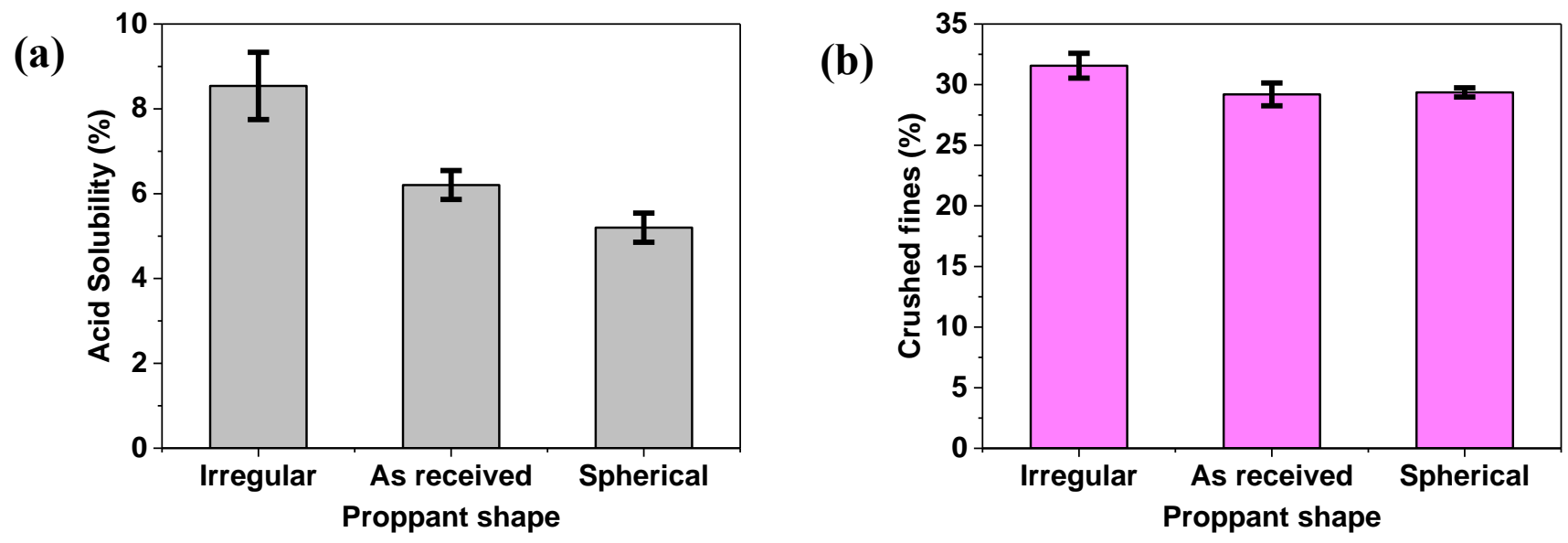

Figure 15 Performance of resin-coated proppants of different shapes (prepared by the RT process with the initial/final temperature of $145 / 195^{\circ} \mathrm{C}$ ).

\section{Conclusion}

Improving particle performance via polymer coatings is of interest to the oil and gas industry as well as many other industries. In this study, solid particles (proppants) were coated with novolac phenolic resin using a hot-melt coating process and the resin was subsequently cured in-situ to form a cross-linked coating layer. Resin coatings significantly improved the performance of proppants in terms of their resistance to acid attack measured using an acid solubility test, and high-pressure crushing measured using a crush resistance test. Challenges in developing a coating process that provides optimal proppant performance stem from the complex coupling between its multiple underlying physical and chemical processes, including the flow of resin melt, distribution and diffusion of HMTA, resin/HMTA curing reaction, particle aggregation and breaking apart as well as heat-induced damages to the resin structure. A delicate balance between these processes is required for optimal coating outcome. Temperature plays a central role in controlling these processes. Different process temperature profiles, including those with constant and ramping temperatures, were explored. In the case of resin coating and curing at constant temperature, lower constant temperatures were found to be more favorable for smooth surface morphology, whereas higher temperatures were needed for a strong and impermeable layer (even though more resin coating layer defects may be present). This dilemma reflects the complex dynamics between the curing kinetics and the mass transfer process: lower temperatures slow down the curing reaction and allow sufficient time for the uniform distribution of the 
crosslinking agent into the resin coating layer, whereas higher temperatures are needed to reach high conversion and crosslinking density. This conflict can be reconciled by a controlled temperature ramp, from which excellent surface quality is achieved without significantly sacrificing the coating performance. The coating performance itself, measured by acid and crush tests, is however not improved compared with the constant temperature process. This is due to the longer retention time of the process, which subjects the resin to prolonged exposure to heat and causes damages in its microscopic structure. Since the duration required for temperature ramp is eventually limited by the rate of heat transfer from the reactor heating jacket to the reactor and its contents, it is concluded that a constant high temperature is still preferred for optimal coating performance in terms of acid solubility and crush resistance performance. Resin coating using ramping temperature is applicable when surface morphology is of concern. This study not only provides an efficient and scalable proppant-coating process optimized for application in hydraulic fracturing operations, the strategy demonstrated here is also generalizable to particle coating processes in many other industries.

\section{Acknowledgment}

The authors gratefully acknowledge the financial support from the Natural Sciences and Engineering Research Council of Canada (NSERC) through its Engage Grants Program (No. EGP-470072-14).

\section{Reference}

(1) Goldschmidt, A.; Streitberger, H.-J. BASF handbook on basics of coating technology; Vincentz Network: Hannover, 2007.

(2) Wicks Jr, Z. W.; Jones, F. N.; Pappas, S. P.; Wicks, D. A. Organic coatings: science and technology; John Wiley \& Sons: Hoboken, 2007.

(3) Donaldson, E. C.; Alam, W.; Begum, N. Hydraulic Fracturing Explained: Evaluation, Implementation, and Challenges; Gulf Publishing: Houston, 2013.

(4) Fink, J. Hydraulic Fracturing Chemicals and Fluids Technology; Gulf Professional Publishing: Waltham, 2013. 
(5) Zoveidavianpoor, M.; Gharibi, A. Application of polymers for coating of proppant in hydraulic fracturing of subterraneous formations: A comprehensive review. J. Nat. Gas Sci. Eng. 2015, 24, 197.

(6) Zhang, K. Resin coated proppant slurry compositions and methods of making and using same. US Patent No. $20100256024,2008$.

(7) Nelson, E. B.; Brown, J. E.; Card, R. J. Sand control without requiring a gravel pack screen. US Patent No. $5551514,1996$.

(8) McLennan, J.; Walton, I.; Moore, J.; Brinton, D.; Lund, J. Proppant backflow: Mechanical and flow considerations. Geothermics 2015, 57, 224.

(9) Liang, F.; Sayed, M.; Al-Muntasheri, G. A.; Chang, F. F.; Li, L. A comprehensive review on proppant technologies. Petroleum 2016, 2, 26.

(10) Pangilinan, K. D.; Al Christopher, C.; Advincula, R. C. Polymers for proppants used in hydraulic fracturing. J. Pet. Sci. Eng. 2016, 145, 154.

(11) Naderhoff, B.; Toman, A. Resin coated particulates. US Patent No. 20110160101, 2010.

(12) Lecomte, F.; Siepmann, J.; Walther, M.; MacRae, R. J.; Bodmeier, R. pH-sensitive polymer blends used as coating materials to control drug release from spherical beads: importance of the type of core. Biomacromolecules 2005, 6, 2074.

(13) Sun, Y.-M.; Chang, C.-C.; Huang, W.-F.; Liang, H.-C. Fluidized-bed spray coated porous hydrogel beads for sustained release of diclofenac sodium. J. Controlled Release 1997, 47, 247.

(14) Karches, M.; Morstein, M.; Von Rohr, P. R.; Pozzo, R. L.; Giombi, J. L.; Baltanás, M. A. Plasma-CVDcoated glass beads as photocatalyst for water decontamination. Catal. Today 2002, 72, 267.

(15) Swayampakula, K.; Boddu, V. M.; Nadavala, S. K.; Abburi, K. Competitive adsorption of Cu (II), Co (II) and Ni (II) from their binary and tertiary aqueous solutions using chitosan-coated perlite beads as biosorbent. $J$. Hazard. Mater. 2009, 170, 680.

(16) Hasan, S.; Krishnaiah, A.; Ghosh, T. K.; Viswanath, D. S.; Boddu, V. M.; Smith, E. D. Adsorption of divalent cadmium (Cd (II)) from aqueous solutions onto chitosan-coated perlite beads. Ind. Eng. Chem. Res. 2006, 45,5066 . 
(17) Martin, C.; Ramirez, L.; Cuellar, J. Stainless steel microbeads coated with sulfonated polystyrene-codivinylbenzene. Surf. Coat. Technol. 2003, 165, 58.

(18) Tracton, A. A. Coatings technology handbook; CRC press: Boca Raton, 2005.

(19) Song, J.; Batra, A.; Rego, J. M.; Macosko, C. W. Polyethylene/polyurethane blends for improved paint adhesion. Prog. Org. Coat. 2011, 72, 492.

(20) O'Connor, A. E.; Macosko, C. W. Melt versus solvent coating: Structure and properties of blockcopolymer-based pressure-sensitive adhesives. J. Appl. Polym. Sci. 2002, 86, 3355.

(21) Patcas, F. C.; Garrido, G. I.; Kraushaar-Czarnetzki, B. CO oxidation over structured carriers: A comparison of ceramic foams, honeycombs and beads. Chem. Eng. Sci. 2007, 62, 3984.

(22) Balkus, K. J.; Scott, A. S. Molecular sieve coatings on spherical substrates via pulsed laser deposition. Microporous Mesoporous Mater. 2000, 34, 31.

(23) Balkus, K. J.; Scott, A. S. Zeolite coatings on three-dimensional objects via laser ablation. Chem. Mater. 1999, 11, 189.

(24) Turton, R.; Cheng, X. X. The scale-up of spray coating processes for granular solids and tablets. Powder Technol. 2005, 150, 78 .

(25) Wesdyk, R.; Joshi, Y.; Jain, N.; Morris, K.; Newman, A. The effect of size and mass on the film thickness of beads coated in fluidized bed equipment. Int. J. Pharm. 1990, 65, 69.

(26) Weiss, K. D. Paint and coatings: a mature industry in transition. Prog. Polym. Sci. 1997, 22, 203.

(27) Bauer, F.; Decker, U.; Dierdorf, A.; Ernst, H.; Heller, R.; Liebe, H.; Mehnert, R. Preparation of moisture curable polysilazane coatings: Part I. Elucidation of low temperature curing kinetics by FT-IR spectroscopy. Prog. Org. Coat. 2005, 53, 183.

(28) Licari, J. J. Coating Materials for Electronic Applications: Polymers, Processing, Reliability, Testing; William Andrew: Norwich, 2003.

(29) Chattopadhyay, D. K.; Raju, K. V. S. N. Structural engineering of polyurethane coatings for high performance applications. Prog. Polym. Sci. 2007, 32, 352. 

cotton fibers: UV curing in comparison with thermal polymerization. Fibers Polym. 2012, 13, 191.

(31) Nikkola, J.; Mahlberg, R.; Mannila, J.; Jämsä, S. Effect of curing process on simulated antisoiling properties of sol-gel coating on pine sapwood. J. Coat. Technol. Res. 2010, 7, 441.

(32) Chico, B.; Galván, J.; De La Fuente, D.; Morcillo, M. Electrochemical impedance spectroscopy study of the effect of curing time on the early barrier properties of silane systems applied on steel substrates. Prog. Org. Coat. 2007, 60, 45 .

(33) Wang, X.; Li, G.; Li, A.; Zhang, Z. Influence of thermal curing on the fabrication and properties of thin organosilane films coated on low carbon steel substrates. J. Mater. Process. Technol. 2007, 186, 259.

(34) Fernandes, B. S.; da Silva Souza, K. G.; Aoki, I. V.; de Melo, H. G.; Amado, F. D. R. Evaluation of the influence of experimental parameters in the formation of a vinyltrimethoxysilane film on 1010 carbon steel through electrochemical impedance spectroscopy and contact angle techniques. Electrochim. Acta 2014, 124, 137.

(35) Lee, S. S.; Han, H. Z.; Hilborn, J. G.; Månson, J.-A. E. Surface structure build-up in thermosetting powder coatings during curing. Prog. Org. Coat. 1999, 36, 79.

(36) Barletta, M.; Lusvarghi, L.; Mantini, F. P.; Rubino, G. Epoxy-based thermosetting powder coatings: surface appearance, scratch adhesion and wear resistance. Surf. Coat. Technol. 2007, 201, 7479.

(37) Yang, L.; Feng, J.; Zhang, W.; Qu, J.-e. Film forming kinetics and reaction mechanism of $\gamma$ glycidoxypropyltrimethoxysilane on low carbon steel surfaces. Appl. Surf. Sci. 2010, 256, 6787.

(38) Wang, Y.; Lieberman, M. Growth of ultrasmooth octadecyltrichlorosilane self-assembled monolayers on SiO2. Langmuir 2003, 19, 1159.

(39) Vallant, T.; Brunner, H.; Mayer, U.; Hoffmann, H.; Leitner, T.; Resch, R.; Friedbacher, G. Formation of self-assembled octadecylsiloxane monolayers on mica and silicon surfaces studied by atomic force microscopy and infrared spectroscopy. J. Phys. Chem. B 1998, 102, 7190.

(40) Graham, J. W.; Sinclair, A. R. High strength particulates. US Patent No. 4585064, 1986.

(41) Johnson, C. K.; Armbruster, D. R. Particles covered with a cured infusible thermoset film and process for their production. US Patent No. 4439489, 1984. 
(42) Sinclair, A. R.; Richard, L. J. I. Composite and reinforced coatings on proppants and particles. US Patent No. 5597784, 1997.

(43) Armbruster, D. R. Precured coated particulate material. US Patent No. 4694905, 1987.

(44) Dewprashad, B. Method of producing coated proppants compatible with oxidizing gel breakers. US Patent No. 5420174, 1995.

(45) Murphey, J. R.; Totty, K. D. Continuously forming and transporting consolidatable resin coated particulate materials in aqueous gels. US Patent No. 4829100, 1989.

(46) American Petroleum Institute (API) API RP 19C: Measurement of Properties of Proppants Used in Hydraulic Fracturing and Gravel-packing Operations; API: Washington, DC, 2008.

(47) Sangaj, N. S.; Malshe, V. Permeability of polymers in protective organic coatings. Prog. Org. Coat. 2004, $50,28$.

(48) Lin-Gibson, S.; Baranauskas, V.; Riffle, J.; Sorathia, U. Cresol novolac-epoxy networks: properties and processability. Polymer 2002, 43, 7389.

(49) Xiaoqing, Z.; Looney, M. G.; Solomon, D. H.; Whittaker, A. K. The chemistry of novolac resins: 3. 13C and $15 \mathrm{~N}$ nmr studies of curing with hexamethylenetetramine. Polymer 1997, 38, 5835.

(50) Katovic, Z.; Stefanic, M. Intermolecular hydrogen bonding in novolacs. Ind. Eng. Chem. Prod. Res. Dev. 1985, 24, 179.

(51) Wang, X.-M.; Riedl, B.; Christiansen, A.; Geimer, R. Differential scanning calorimetry of the effects of temperature and humidity on phenol-formaldehyde resin cure. Polymer 1994, 35, 5685.

(52) Zhang, C.; Binienda, W. K.; Zeng, L.; Ye, X.; Chen, S. Kinetic study of the novolac resin curing process using model fitting and model-free methods. Thermochim. Acta 2011, 523, 63.

(53) De Medeiros, E. S.; Agnelli, J. A.; Joseph, K.; De Carvalho, L. H.; Mattoso, L. H. Curing behavior of a novolac-type phenolic resin analyzed by differential scanning calorimetry. J. Appl. Polym. Sci. 2003, 90, 1678. 


\section{For Table of Contents Only}

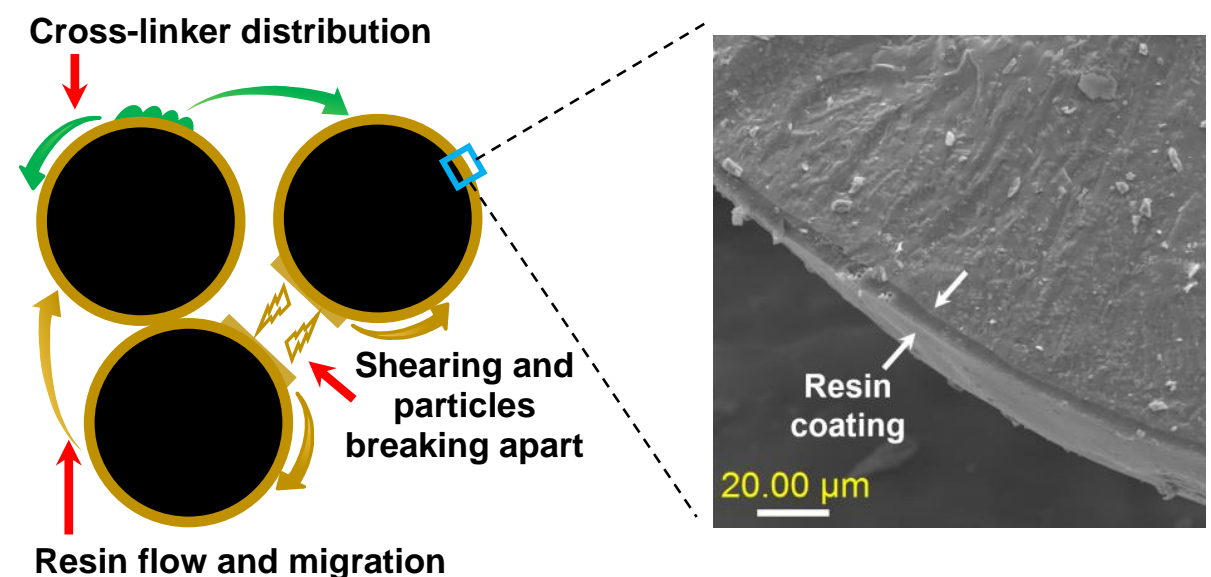

